\title{
Surgical Management of Tumours Invading the Skull Base
}

\author{
P.J. Derome
}

\begin{abstract}
The author describes four different approaches to clival tumours, and reviews his experience with 33 chordomas of the clivus. He also reviews his large experience with tumours invading the floor of the anterior and middle cranial fossae, and describes various surgical approaches for the removal of these tumours, followed by reconstruction of the bony floor with bone grafts, and dural reconstruction.
\end{abstract}

RÉSUMÉ: Traitement chirurgical des tumeurs envahissant la base du crâne L'auteur présente quatre approches différentes au traitement des tumeurs du clivus et revoit son expérience avec 33 chordomes du clivus. Il passe également en revue les résultats de son expérience avec les tumeurs envahissantes des fosses antérieures et médianes. L'auteur décrit les diverses approches chirurgicales pour l'exérèse de ces tumeurs, la reconstruction du plancher osseux avec des greffes osseuses et la reconstruction de la dure-mère.

Can. J. Neurol. Sci. 1985: 12:345-347

\section{The Clival Area}

Because of its deep localization at the middle of the skull base, surgical access to the clivus is difficult; nevertheless, many approaches lead to the clival area from inside or from outside the skull. $1,2,3,4.5$

When a tumour grows intracranially without destroying bone, the most logical approach is the classical transdural approach. In the case of meningiomas, except perhaps for the lateral infratemporal route described by Fisch, ${ }^{6}$ extradural approaches are dangerous because of their narrowness, the relationship of the tumour to the brainstem and nervous and vascular structures of the posterior fossa, and the risk of post-operative CSF leaks when the clivus is reached through the nasal or buccal cavities. Depending on its main extension, a clival meningioma may be approached through the subtemporal route dividing the tentorium, the suboccipital infratentorial route, or, in extensive lesions, through the petrosal route described by Malis (Personal Communication) which combines a subtemporal and suboccipital approach with division of the tentorium.

In contrast, chordomas can be reached through a more narrow anterior approach in much the same way as a huge enclosed pituitary adenoma may be removed through the transphenoidal route. This is possible because chordomas are usually of soft consistency. They originate from the notochord and are at first extradural, invading and destroying the bone. We will describe in sequence the transcervical, transoral, transphenoidal and transbasal approaches for chordomas, which are detailed and illustrated elsewhere. $^{3}$

The transcervical (described by Stevenson) ${ }^{7}$ and the transoral approaches lead to the lower half of the clivus. The transcervical route is safer in case of accidental (or intentional) opening of the dura, since it does not pass through the oral cavity. The transoral approach is easier to perform; the soft palate is divided in the midline, but the resulting triangular exposure does not always provide a sufficient field of vision for the upper pole of the tumour if it extends higher than the lower half of the clivus. Extension of the incision along the back of the hard palate, turning the soft tissue back along the dental arches, allows elevation of the entire fibro mucosa in two flaps and an ample quadrangular exposure which is very useful in extensive chordomas. This approach also permits a wider lateral field of vision which is not available with the transcervical approach. If necessary the anterior arch of $\mathrm{Cl}$ and the odontoid process may be resected. It is difficult to appreciate from the preoperative CT scans and radiographs the exact extent of the tumour in relation to the dura. Fortunately many chordomas have neither destroyed nor yet invaded the dura and for this reason the transoral approach is tried first in doubtful cases.

The next approach is the transphenoidal route to the sellar floor, such as is used for the removal of pituitary tumours. When 
a chordoma has destroyed the upper half of the clivus and invades the sella and the sphenoid sinus, it is often possible to perform an extensive subtotal removal because of the soft consistency of the tumour. However, as with pituitary tumours, tough, fibrous lesions cannot be extracted by this approach.

The transbasal (subfrontal) approach ${ }^{3}$ allows access to chordomas of the upper half of the clivus when they spread anteriorly into the sphenoidal body and sinuses, bulge into the anterior fossa and cause extradural compression of the optic nerves. In spite of the high level of the exposure between the optic nerves, this approach allows the surgeon to go very deeply during the removal of the tumour, between the cavum mucosae and the clivus. It is possible to reach inferiorly as far as the anterior rim of the foramen magnum, the anterior arch of the atlas and even the body of $\mathrm{C} 2$. But the field of vision is limited posteriorly with the dura stretched between the extradural portion of the optic nerves and the bulging sella.

The transbasal approach may be combined with a rhinoseptal approach during the same surgical procedure. This adds the advantages of the two techniques, and the transphenoidal approach allows removal of the posterior pole of the tumour, bulging in the posterior fossa, and which is totally hidden for the neurosurgeon working subfrontally and transbasally. This combined approach is probably the best one for chordomas of the upper half of the clivus spreading posteriorly and anteriorly.

Chordomas are not usually malignant. However, they are locally invasive and cannot be totally removed. The more extensive the removal, the better the chances of a long survival. The choice of the best approach or the combination of multiple approaches in one, two or even three stages allow optimal removal. Of course the approach must be designed to permit relief of the patient's symptoms. To summarize the different approaches for chordomas, the intradural route is used only for lateral localizations in the petrous bone or temporal and subtemporal areas. Midline chordomas are best reached through the extradural anterior approaches depending on the level of the clivus involved. Our experience with single and multiple approaches for removal of chordomas is summarized in Tables 1 and 2.

\section{The Anterior and Middle Fossae}

A variety of tumours may invade the base of the skull; these include primary bone tumours such as fibrous dysplasias, chordomas, chondromas, osteoblastomas and ossifying fibromas. The skull base may be invaded by a tumour arising nearby, such as a meningioma. The difficulties encountered in their surgical management depend on the relation of the tumour to the dura and the upper air-filled cavities of the face (frontal sinuses, ethmoidal cells, sphenoidal sinus, nasal fossae). A meningioma "en plaque" growing laterally may be removed totally without any risk of spinal fluid leak and without the need for bony reconstruction; but removal of midline en plaque meningiomas will open widely the nasal cavities or the adjacent sinuses.

Of course, if the dura is invaded or destroyed there is a high risk of CSF leak. A careful and watertight closure of the subfrontal dura is mandatory; the ease of dural repair depends on the extent of the dural defect; tears must be carefully sutured, and strengthening of the subfrontal dura in the midline is advisable. The best material, because it is a living material and because of its adherence capabilities is the pericranium; it is readily avail- able through the same scalp incision. This material is used in case of dural destruction, overlapping widely the edges of the defect. In tumours spreading posteriorly, reaching the turberculum sellae, it is not possible to suture the graft because of lack of normal dura; in such cases a large pericranial graft may be applied to the subfrontal dura and folded posteriorly on the skull base, like a leaf of a book, but a water tight closure cannot be achieved immediately; two or three months are necessary between the removal of the intracranial part of the tumour (followed by dural repair) and the removal of its basal part invading the nasal fossae or the sphenoidal sinuses. The management of basal lesions in one or two surgical steps depends on the possibility of achieving a water tight closure of the dura during the first procedure.

Reconstruction of the midline bony floor of the anterior cranial fossae is also advisable in most cases; destruction of the ethmoidal and sphenoidal areas may result in a large and wide dead space, with risk of post operative hematoma, infection, epidural pneumatocoele and, as was observed in one case, secondary displacement of the brain mass with visual complications. Close to the potentially infected cavities of the face, the skull base should be repaired with bone autografts; cancellous grafts are better than cortical grafts; in adults, the grafts are taken from the iliac wing; in childhood from the cranial vault or from ribs. When the nasal fossae are widely opened and the mucosae destroyed, the grafts are applied above an anterior pericranial flap which is turned posteriorly.

With careful attention to closure and repair of the different layers including dura, bone and mucosa, surgery of the base of the anterior fossa remains quite safe. The first goal of surgery is the total or the most total possible removal of the tumour and pathologic bone; the technical limits depend mainly on the extent of dural invasion towards the cavernous sinuses. To free the cranial nerves is the second goal: optic nerves in the optic canals, oculomotor nerve in the superior orbital fissure, maxillary nerve in the foramen rotondum and mandibular nerve in the foramen ovale. Correction of large deformities such as occur in fibrous dysplasias is the third goal of surgery.

\begin{tabular}{lc}
\hline Table 1: Single Approaches Used in 33 Chordomas \\
\hline \hline \\
Intradural Approach: & \\
- Subfrontal - Pterional & 4 \\
- Temporal & 4 \\
- Suboccipital & 3 \\
Extradural Approach: & 15 \\
- Transphenoidal & 3 \\
- Transbasal & 4 \\
- Transoral & \\
\hline
\end{tabular}

Table 2: Multiple Approaches Used in 10 Chordomas

Transbasal + Transphenoidal

Transbasal + Transoral

Transbasal + Transphenoidal + Transoral

Transbasal + Transphenoidal + Temporal

Transbasal + Transoral + Temporal

Transphenoidal + Temporal

Transoral + Temporal 
Table 3: 102 Cases of Basal Tumours Operated On Transbasally up to June 1984

\begin{tabular}{lr}
\hline & \\
Fibrous Dysplasias & 42 \\
Meningiomas (Invasive) & 28 \\
Chordomas & 10 \\
Chondromas & 5 \\
Olfactory Placod Tumours & 5 \\
Osteoblastomas & 3 \\
Ossifying Fibromas & 3 \\
Osteomas & 2 \\
Sarcomas & 2 \\
Cylindromas & 1 \\
Hemangiopericytoma & 1 \\
\hline
\end{tabular}

In our experience at Hospital Foch, the most frequent benign lesions operated on are meningiomas and fibrous dysplasias, followed by chordomas, chondromas and ossifying fibromas. (Table 3)

There are two kinds of meningiomas. Hyperostosing meningiomas "en plaque" grow in the lateral part of the sphenoid; they are responsible for exophthalmos and late compression of the optic nerve; it is necessary to remove not only the hyperostosis (which is always pathological bone) but also the temporal meningeal plaque and very often the orbital plaque; the air filled cavities of the face are not opened by this removal and bone repair is not necessary if the temporal muscle is carefully reinserted on the frontal bone flap. By contrast, meningiomas "en masse" invading the base of the skull grow medially and very often spread into the sphenoid and ethmoid sinuses and nasal fossae; the technical conditions for their safe removal have been described above. Careful attention must be given to removal of the frequent basal invasion that occurs in olfactory meningiomas and meningiomas of the jugum and tuberculum sellae, because this invasion may be responsible for late intracranial and basal recurrences; most of the operations we have done for these lesions have been in patients with tumour recurrences.
Fibrous dysplasia ${ }^{8}$ often causes progressive orbitocranial deformity, exophthalmos and impaired vision; when visual failure occurs, it is very often severe, with unilateral blindness. Surgical treatment planning is based on the natural history of fibrous dysplasia; the disease occurs in young patients and is usually stable after the age of 25 or 30 years; there are two periods during which fibrous dysplasia undergoes active evolution: the first one during the first decade of life (with a predominance of cystic forms and huge deformities), and the second between 12 and 22 years. Surgery is mandatory in cases with visual disturbances; in other cases preventive surgery may be proposed if the patient is young ( $<25$ years old), if the optic foramina are included in the dysplasia and if it is an heterogenous and cystic form which often progresses more actively than the sclerotic form.

\section{REFERENCES}

1. Derome PJ et al. Les tumeurs sphéno-ethmoidales - Possibilites d'exérèse et de réparation chirurgicales. Neurochirurgie Suppl l 1972; 18:164.

2. Derome PJ. La voie trans-bucco-pharyngée et la pathologie tumorale du clivus. Neurochirurgie 1977; 23:298-306.

3. Derome PJ. The transbasal approach to tumours invading the base of the skull. In: Schmidek H, Sweet WM, eds. Operative Neurosurgical Techniques. Indications, Methods and Results. New York: Grune and Stratton Vol. 1, 1982:357-379.

4. Derome PJ, Guiot G. Bone problems in meningiomas invading the base of the skull. Clin Neurosurg 1978; 25:435-451.

5. Derome PJ, Guiot $\mathbf{G}$ et al. Surgical approaches to the sphenoidal and clival areas. I $n$ : Krayenbuhl, ed. Advances and Technical Standards in Neurosurgery 1979; 6:101-136.

6. Fisch U, Pillsburg HC. Infratemporal approach to the lesions in the temporal bone and base of the skull. Arch Oto-Laryngol 1979; 105:99-107.

7. Stevenson GC, Stoney RJ, Perkins RK et al. A transcervical transclival approach to the ventral surface of the brainstem for removal of a clivus chordoma. J Neurosurg 1966; 24:544-551.

8. Derome PJ, Visot A et al. Fibrous dysplasia of the skull. Neurochirurgie 1983; 29:1-117 Suppl. 